Annuaire suisse de politique de développement

$11 \mid 1992$

Annuaire Suisse - Tiers Monde 1992

\title{
Ordre du jour de la CNUCED : préparation de la
} Suisse

Vorbereitung und Schwerpunkte der Schweiz zu den Traktanden der UNCED

Thomas Litscher

\section{(2) OpenEdition}

\section{Journals}

Édition électronique

URL : http://journals.openedition.org/aspd/1584

DOI : $10.4000 /$ aspd. 1584

ISSN : 1663-9669

Éditeur

Institut de hautes études internationales et du développement

\section{Édition imprimée}

Date de publication : 1 janvier 1992

Pagination : 183-187

ISSN : 1660-5934

\section{Référence électronique}

Thomas Litscher, "Ordre du jour de la CNUCED : préparation de la Suisse », Annuaire suisse de politique de développement [En ligne], 11 | 1992, mis en ligne le 19 mai 2013, consulté le 08 septembre 2020.

URL : http://journals.openedition.org/aspd/1584 ; DOI : https://doi.org/10.4000/aspd.1584

Ce document a été généré automatiquement le 8 septembre 2020.

(C) The Graduate Institute / Geneva 


\section{Ordre du jour de la CNUCED : préparation de la Suisse}

Vorbereitung und Schwerpunkte der Schweiz zu den Traktanden der UNCED

\section{Thomas Litscher}

\section{NOTE DE L'ÉDITEUR}

Lire l'article original en allemand dans Schweizerisches Jahrbuch für Entwicklungspolitik:

"Vorbereitung und Schwerpunkte der Schweiz zu den Traktanden der UNCED ", http://sjep.revues.org/1379. 